\title{
Treatment Outcomes of Clopidogrel in Patients With ACS and Diabetes Undergoing PCl-analysis of Beijing Medicare Database
}

\section{Weihao Wang}

Department of Endocrinology, Beijing Hospital, National Center of Gerontology; Institute of Geriatric Medicine, Chinese Academy of Medical Sciences, Beijing, P.R. China

\section{Xiaoxia Wang}

Department of Endocrinology, Beijing Hospital, National Center of Gerontology; Institute of Geriatric Medicine, Chinese Academy of Medical Sciences, Beijing, P.R. China

\section{Lina Zhang}

Department of Endocrinology, Beijing Hospital, National Center of Gerontology; Institute of Geriatric Medicine, Chinese Academy of Medical Sciences, Beijing, P.R. China

\section{Jie Zhang}

Department of Endocrinology, Beijing Hospital, National Center of Gerontology; Institute of Geriatric Medicine, Chinese Academy of Medical Sciences, Beijing, P.R. China

\section{Fuli Man}

Department of Endocrinology, Beijing Hospital, National Center of Gerontology; Institute of Geriatric Medicine, Chinese Academy of Medical Sciences, Beijing, P.R. China

\section{Qi Pan}

Department of Endocrinology, Beijing Hospital, National Center of Gerontology; Institute of Geriatric Medicine, Chinese Academy of Medical Sciences, Beijing, P.R. China

\section{Lixin Guo ( $\square$ glxwork2016@163.com )}

Department of Endocrinology, Beijing Hospital, National Center of Gerontology; Institute of Geriatric Medicine, Chinese Academy of Medical Sciences, Beijing, P.R. China https://orcid.org/0000-0003-26098387

\section{Original investigation}

Keywords: clopidogrel, mortality, diabetes, PCl, medicare database

Posted Date: August 4th, 2020

DOl: https://doi.org/10.21203/rs.3.rs-49213/v1 
License: (c) (i) This work is licensed under a Creative Commons Attribution 4.0 International License. Read Full License 


\section{Abstract \\ Background}

There are several clinical trials that proved the efficacy of clopidogrel treatment for patients with percutaneous coronary intervention. There are few large-scale research to explore the mortality associated with different duration use of clopidogrel in patients with diabetes and ACS undergoing PCI in the Chinese population.

\section{Objectives}

The objective of this analysis was to determine the efficacy of long-term clopidogrel therapy $(\geq 12$ months) versus short-term use $(<12$ months $)$ in Chinese patients with diabetes after $\mathrm{PCl}$.

\section{Methods}

Using the Beijing Medicare database provided by Beijing Medical Security Bureau. The Beijing Medicare database contains medical data of about 16 million people, including about 990,000 patients with diabetes and a history of taking antidiabetic medicines. Patients were divided into two groups, one group of 9,116 patients receiving consecutive clopidogrel for one year or more, and another group of 3290 patients receiving consecutive clopidogrel less than one year. The primary of this analysis was the risk of all-cause death, myocardial infarction and revascularization.

\section{Results}

In patients with diabetes after $\mathrm{PCl}$, long-term clopidogrel treatment was associated with a reduced risk of all-cause death ( $\mathrm{HR}, 0.57[95 \% \mathrm{Cl}, 0.49-0.67], \mathrm{P}<0.0001)$, myocardial infarction( $\mathrm{HR}, 0.79[95 \% \mathrm{Cl}, 0.68-$ $0.93], \mathrm{P}=0.0035)$ and an increased risk of angina $(\mathrm{HR}, 1.18[95 \% \mathrm{Cl}, 1.10-1.27], \mathrm{P}<0.0001])$ and revascularization( $\mathrm{HR}, 1.07[95 \% \mathrm{Cl}, 1.01-1.13], \mathrm{P}=0.02])$. There was no significant difference in the incidence of all-cause re-hospitalization $(P=0.7529)$, diabetes-related re-hospitalization and cerebrovascular re-hospitalization.

\section{Conclusion}

The present study concluded that long-term dual anti-platelet therapy including clopidogrel and aspirin could decrease the risks of all-cause death, myocardial infarction. But it could increase the risks of angina and revascularization. Further studies should interpret the cause of this question.

\section{Introduction}


There are several clinical trials that proved the efficacy of clopidogrel treatment for patients with the percutaneous coronary intervention $(\mathrm{PCl})^{1,2}$. For patients with $\mathrm{PCl}$, current guidelines suggest clopidogrel treatment for at least 12 months $^{3}$. Non-adherence with clopidogrel after coronary stent implantation could be related to some adverse like increased mortality ${ }^{4}$. Diabetes is one of the four significant noncommunicable diseases and is a major cause of premature death and disability. Among patients with diabetes, the adherence therapy of clopidogrel after myocardial infarction leads to a lower induction in the risk of death(all-cause death and cardiovascular death) ${ }^{5}$ compared with it in patients without diabetes. It is well known that patients accompanied by diabetes and acute coronary syndrome(ACS) undergoing $\mathrm{PCl}$ are at higher risk for some adverse effects like death ${ }^{6}$. The prevalence of diabetes in China has increased 10 -fold in the past decade and reached 114 million, making it the country with the highest diabetic population in the world ${ }^{7,8}$. Among Chinese patients with ACS, $37.6 \%$ accompanied diabetes or possible diabetes. Even in patients with diabetes younger than 45 years old, $26.9 \%$ accompanied by diabetes or possible diabetes ${ }^{9}$. There are few large-scale research to explore the mortality associated with different duration use of clopidogrel in patients with diabetes and ACS undergoing $\mathrm{PCl}$ in the Chinese population.

All medicare citizens are registered with a personal number in China. Since the establishment of China's medicare system, there has been little relevant large-scale clinical data analysis. Beijing medicare system covers medical data of thousands of hospitals and community clinics.

In China, the length of clopidogrel therapy is consistent with guidelines. We conducted large-scale research of $12406 \mathrm{PCl}$ treated patients with diabetes to evaluate the effect of different duration use of clopidogrel on mortality and other indicators.

\section{Methods}

\section{Data Source}

In China, all medicare citizens are registered with a personal number in the Medicare System. The Beijing Medical Security Bureau holds all the information on all outpatients and hospitalizations in Beijing. The Medicare System records all the prescriptions and diagnosis information dispensed from hospitals and clinics in Beijing. For calculating the expenses of medicare, all the treatment and use of drugs are registered in the Medicare System in China. The study was approved by the ethics committee of Beijing Hospital.

\section{Population}

The population included in this study were all enrolled in the Beijing Medical Security Bureau with available treatment records from 2012-2016. First of all, patients with diabetes diagnoses were searched in Medicare System. Then among the patients with diabetes, PCI treatment was identified to locate the 
patients diagnosed with acute coronary syndrome and diabetes. Patients with survival days of less than 30 days were excluded. Diabetic patients who had at least one time $\mathrm{PCl}$ treatment were eligible for further selection. Then patients who have continuous treatment $(\geq 1$ year) of aspirin were selected for further investigation in this research. The Beijing Medicare System contains demographic and clinical data like age, sex, history and time of drug use and surgery treatment. The data extracted from the Medicare System contains all medical prescriptions and surgery history.

\section{Medication Therapy}

The Beijing Medical Security Bureau provided medications and diagnosis used from 2012-2016 in patients with diabetes after $\mathrm{PCl}$. Since the drug name appearing in the medicare system may be the chemical name or trade name, we classified the drugs into categories according to the clinical guidelines, such as metformin, sulfonylurea, DPP-4 inhibitors, thiazolidinediones(TZDs), a-glucosidase inhibitors and glinides (hypoglycemic drugs), diuretics, CCBs, ARB/ACEl, $\beta$-receptor inhibitors(antihypertensive drugs), etc. We tracked the dates of prescription of aspirin and clopidogrel up to 4 years after PCl. Patients were considered as not taking aspirin or clopidogrel if the prescription lapsed over 30 days from the last day of the supply. Clopidogrel use was defined as either long-term( $\geq 12$ months therapy after $\mathrm{PCl})$ or short term( $<12$ months therapy after $\mathrm{PCl})$ therapy.

\section{Outcomes}

Clinical outcomes in patients with diabetes after PCI were identified from the Beijing Medical Security Bureau through the medicare system until December 2016. These outcomes included all-cause death, myocardial infarction, all-cause re-hospitalization, diabetes-related re-hospitalization, cerebrovascular rehospitalization, angina and revascularization.

\section{Statistical Analysis}

Quantitative variables were expressed as mean \pm SD and categorical variables as frequencies and percentages. Continuous variables with normal distribution were compared between the two groups by the t-test and continuous variables without normal distribution by the Wilcoxon rank-sum test. Categorical variables were compared between groups using the chi-square test or Fisher's exact probability method (when the expected frequency of cells greater than $25 \%$ is less than 5 ). Events were summarized with Kaplan-Meier curves and estimates at three years. Hazard ratios (HRs) comparing treatment groups were derived from univariate Cox regression models. Subgroups were analyzed with a Cox model, including subgroup, treatment, and the subgroup-by-treatment interaction. Multivariate Cox regression models were derived for the event by the use of a backward selection algorithm. The significance level for staying in the model was set to 0.05 two-sides. All data were prospectively analyzed using the SAS, version 9.4 . 


\section{Results}

\section{Population Selection}

The selection process was showed in Fig. 1. The Beijing Medicare database contains medical data of about 16 million people, including about 990,000 patients with diabetes and a history of taking antidiabetic medicines. Among them, 18,799 patients had a record of $\mathrm{PCl}$ surgery in 2014-2016. Among them, 13,693 patients have continuous aspirin withdrawal records in the medicare system. After excluding patients with a survival time of less than one year or no continuous clopidogrel medication withdrawal records, the patients were divided into two groups, one group of 9,116 patients receiving consecutive clopidogrel for one year or more, and another group of 3290 patients receiving consecutive clopidogrel less than one year.

\section{Demographics Of Drugs Treatment}

We summarized the medication situation of the two groups of patients as showed in Table 1. Classifications of drugs contains antidiabetic medicine(Thiazolidinediones, a-glucosidase inhibitors, metformin, sulfonylureas, DPP-4 inhibitors, glinides, insulin), antihypertensive medicine(ARB/ACEI, CCB, $\beta$-receptor inhibitors, diuretic), related cardiovascular medicine(statin, nitrate, proton pump inhibitors). In group of patients receiving clopidogrel less than 1 years, $4.5 \%$ patients treated with TZD, $53.4 \%$ with aglucosidase inhibitors, $43.3 \%$ with metformin, $6.5 \%$ with glinides, $25.2 \%$ with sulfonylureas, $0.5 \%$ with DPP-4i, 32.8\% with insulin, 63.4\% with ARB/ACEI, 48.4\% with CCB, $72.8 \%$ with $\beta$-receptor inhibitors, $19.1 \%$ with diuretic, $93.4 \%$ with statin, $0.5 \%$ with ticagrelor, $50 \%$ with nitrate, $16.5 \%$ with PPI more than 1 year. There are $7.0 \%$ patients treated with TZD, $22.2 \%$ with a-glucosidase inhibitors, $23.2 \%$ with metformin, $8.2 \%$ with glinides, $17.2 \%$ with sulfonylureas, $21.2 \%$ with ARB/ACEI, $23.3 \%$ with CCB, $17.4 \%$ with $\beta$ receptor inhibitors, $25.4 \%$ with diuretic, $6.2 \%$ with statin, $3.5 \%$ with ticagrelor, $38.4 \%$ with nitrate, $43.9 \%$ with PPI less than one year. There are $88.5 \%$ patients without treated with TZD, $24.3 \%$ without aglucosidase inhibitors, $33.5 \%$ without metformin, $85.4 \%$ without glinides, $57.6 \%$ without sulfonylureas, $15.3 \%$ without ARB/ACEI, $28.4 \%$ without CCB, $9.8 \%$ without $\beta$-receptor inhibitors, $55.4 \%$ without diuretic, $0.3 \%$ without statin, $96.0 \%$ without ticagrelor, $11.6 \%$ without nitrate, $39.6 \%$ without PPI.

In the group of patients receiving clopidogrel more than one years, $4.0 \%$ patients treated with TZD, $55.6 \%$ with a-glucosidase inhibitors, $45.5 \%$ with metformin, $6.7 \%$ with glinides, $26 \%$ with sulfonylureas, $65.2 \%$ with ARB/ACEI, $52 \%$ with CCB, $77.3 \%$ with $\beta$-receptor inhibitors, $19.4 \%$ with diuretic, $97 \%$ with statin, $0.1 \%$ with ticagrelor, $60 \%$ with nitrate, $17.8 \%$ with PPI more than one year. There are $7.4 \%$ patients treated with TZD, $21.1 \%$ with a-glucosidase inhibitors, $21.3 \%$ with metformin, $8.2 \%$ with glinides, $16.4 \%$ with sulfonylureas, $18.7 \%$ with ARB/ACEI, $21 \%$ with CCB, $13.1 \%$ with $\beta$-receptor inhibitors, $24.6 \%$ with diuretic, $2.7 \%$ with statin, $0.9 \%$ with ticagrelor, $31.2 \%$ with nitrate, $41.7 \%$ with PPI less than one year.

There are $88.6 \%$ patients without treated with TZD, 23.3\% without a-glucosidase inhibitors, $33.3 \%$ without metformin, $85.1 \%$ without glinides, $57.6 \%$ without sulfonylureas, $16 \%$ without ARB/ACEl, $27 \%$ without 
CCB, 9.7\% without $\beta$-receptor inhibitors, $56.1 \%$ without diuretic, $0.3 \%$ without statin, $99 \%$ without ticagrelor, $8.9 \%$ without nitrate, $40.6 \%$ without PPI.

\section{Mortality And Incidence Of Recurrent Myocardial Infarction And Hospitalization}

The mortality was lower in patients treated with clopidogrel more than one year compared with the group treated with clopidogrel less than one year(4.6\% vs 7.7\%, HR, 0.57[95\% Cl, 0.49-0.67], P< 0.0001)(Fig. 2). The incidence of myocardial infarction was lower in patients treated with clopidogrel more than one year compared with patients treated with clopidogrel less than one year(8.2\% vs $10.1 \%, \mathrm{HR}, 0.79[95 \% \mathrm{Cl}, 0.68-$ 0.93], $P=0.0035)$ (Fig. 3). However, there were no significant differences in the incidence of all-cause rehospitalization $(P=0.7529)$, diabetes-related re-hospitalization $(P=0.9727)$ and cerebrovascular rehospitalization( $P=0.2958)$ (Fig. 4-6).

\section{Incidence Of Angina And Revascularization}

The rate of angina and revascularization was 35.8\% and 54.5\% in long-term dual anti-platelet therapy group compared with $31.1 \%$ and $51.8 \%$ in placebo group $(\mathrm{HR}, 1.18[95 \% \mathrm{Cl}, 1.10-1.27], \mathrm{P}<0.0001])(\mathrm{HR}$, $1.07[95 \% \mathrm{Cl}, 1.01-1.13], \mathrm{P}=0.02]$ )(Fig. 7-8). Long-term combination of aspirin and clopidogrel could cause higher risks of angina and revascularization.

\section{Discussion}

From 2012 to 2016, we screened a cohort of 12,406 patients who underwent PCl surgery among 990,000 diabetic patients in Beijing. The results showed that clopidogrel could reduce all-cause mortality and the probability of recurrent myocardial infarction after more than one year's regular treatment, but had no significant effect on all-cause readmission, cerebrovascular readmission and diabetes-related readmission. But long-term dual anti-platelet treatment including aspirin and clopidogrel could increase the risks of angina and revascularization. In the past published articles in the Veterans Health Administration database, in patients with diabetes mellitus who received drug-eluting stents, prolonged clopidogrel(more than 12 months) was associated with a reduced risk of death ${ }^{10}$. This result is consistent with the long-term use of clopidogrel in patients without diabetes ${ }^{11,4}$. However, similar studies on the Chinese medicare database are still lacking.

High risk of poor clinical outcomes were observed in patients with diabetes after $\mathrm{PCl}^{12,13}$. The DAPT study concluded a result that the treatment of thienopyridine beyond one year could decrease the risks of stent thrombosis and major cerebrovascular and cardiovascular events ${ }^{14}$. As expected, long-term dual anti-platelet therapy could increase the risk of bleeding. That was why our results showed that over $50 \%$ of patients had used PPI. However, other research showed that different stents ${ }^{15}$ and P2Y12 inhibitors $^{16}$ 
had been related to different rates of stent thrombosis and myocardial infarction. Our research has not focused on this difference as for inconvenient of the China medicare database to distinguish different stents. The rate of all-cause death and myocardial infarction in the DAPT study was $2.0 \%$ and $2.1 \%$ in the long-term thienopyridine treatment and $1.5 \%, 4.1 \%$ in the placebo group. But in our study, the rate of allcause death and myocardial infarction in the long-term dual anti-platelet therapy group was $4.6 \%$ and $8.1 \%$ compared with $7.7 \%$ and $10.1 \%$ in the placebo group. This was a big difference between the DAPT study and our results. This result also proved that patients with diabetes after $\mathrm{PCl}$ had a higher risk of poor clinical outcomes compared with patients without diabetes. The same aspect between the two studies was that long-term therapy did not affect cerebrovascular outcomes.

Another finding is that long-term dual anti-platelet therapy could increase the risks of angina and revascularization in patients with diabetes undergoing $\mathrm{PCl}$. Controversies still exist with the combination use of clopidogrel and PPI following coronary stenting. The previous meta-analysis ${ }^{17}$ showed that the continuous use of clopidogrel and PPI was associated with higher MACES with OR:1.27, 95\% CI[1.131.42]. Another meta-analysis ${ }^{18}$ found that long-term dual therapy leads to increase MACEs, myocardial infarction, stent thrombosis and target vessel revascularization. Our results showed that $17.8 \%$ of patients with long-term dual therapy and $16.5 \%$ of patients with short-term dual therapy had used PPI for more than one year. That may be the cause of increased rates of angina and revascularization. The possible reason for increased adverse effects was that PPI involved in the same metabolic pathway(CYP2C19 isoenzyme and so on) with that of clopidogrel ${ }^{19}$. However, several studies found different results. From the results of Guthrie Health Off-label Stent(GHOST) research, the combination of $\mathrm{PPI}$ and clopidogrel was not related to any increase in MACEs outcomes after $\mathrm{PCl}^{20}$. The specific conclusion still needs further investigation.

Ticagrelor is the first reversibly binding direct P2Y12 inhibitor. Compared with clopidogrel and prasugrel, it does not need enzymatic activation, and it can inhibit platelets faster, better and more stably compared with clopidogrel ${ }^{21,22}$. Meanwhile, regardless of revascularization or not, ticagrelor could reduce the risk of all-cause death with no significant increase in risk of overall bleeding compared with clopidogrel $^{23}$. Our results showed that over $95 \%$ of diabetic patients after $\mathrm{PCl}$ surgery never used ticagrelor. This may be related to the drug price and the prescription habits of Chinese doctors.

At the same time, we also summarized the medication situation of patients with diabetes and PCl. We found that the most commonly used antidiabetic drug was alpha-glucosidase inhibitors, followed by metformin. According to the guidelines, most of the lipid-lowering drugs selected for patients with diabetes after $\mathrm{PCl}$ are statins ${ }^{3,24}$, which is consistent with our results. More than $90 \%$ of patients have used statins for more than one year. But recent research found that treatment with fenofibrate and metformin produces the cardioprotective effect in acute myocardial infarction and diabetes rat model ${ }^{25}$. And the possible mechanism may interact through PPARa activation.

\section{Limitations}


There was no specific classification of drugs and diseases of the Chinese medicare database.

Researchers achieved the classification, and there was no patients'laboratory indicators in the database. It was hard to distinguish the different types of stents to go through further investigation. This study also did not include more potent anti-platelet agents.

\section{Conclusion}

The present study concluded that long-term dual anti-platelet therapy including clopidogrel and aspirin could decrease the risks of all-cause death, myocardial infarction and did not affect the incidence of allcause re-hospitalization, diabetes-related re-hospitalization and cerebrovascular re-hospitalization in patients with diabetes after $\mathrm{PCl}$. But it could increase the risks of angina and revascularization.

\section{Declarations}

\section{Acknowledgements}

Not applicable.

\section{Authors' contributions}

WWH, XXWand LNZ made substantial contributions to study design, data collection, data analysis and manuscript writing. QP and LXG made substantial contributionsto study design and intellectual direction. JZ and FLM made contributions to data collection and analysis. All authors read and approved the final manuscript.

\section{Funding}

This study was funded by National Natural Science Foundation of China (Grant No. 81670763 and 81471050).

\section{Availability of data and materials}

The datasets used and/or analyzed during the current study are available from the corresponding author on reasonable request.

\section{Ethics approval}

The study protocol was approved by the Ethics Committee of Beijing Hospital.

\section{Consent for publication}

Not applicable.

\section{Competing interests}


The authors declared that they have no conflict of interest.

\section{References}

1. Mehta SR, et al. Effects of pretreatment with clopidogrel and aspirin followed by long-term therapy in patients undergoing percutaneous coronary intervention: the PCI-CURE study. Lancet. 2001;358:52733.

2. Berger PB, Fry ETA, Delago A, Wilmer C, Topol EJ. Early and Sustained Dual Oral Antiplatelet Therapy Following Percutaneous Coronary Intervention-A Randomized Controlled Trial. JAMA 288, (2002).

3. Uk CB, et al. 2017 ESC Guidelines for the management of acute myocardial infarction in patients presenting with ST -segment elevation The Task Force for the management of acute myocardial infarction. Eur Heart J. 2018;39:119-77.

4. Din J, et al. Non-Adherence with Clopidogrel after Coronary Stenting Is Associated with Increased Mortality and Myocardial Infarction. J Am Coll Cardiol. 2013;61:E1596.

5. Andersson C, Nielsen M, Køber L. \& Torp-pedersen, C. Association of Clopidogrel Treatment With Risk of Mortality and Cardiovascular Events Following Myocardial Infarction. JAMA. 2012;308:882-9.

6. Zeymer U, et al THE HIGH EVENT RATE IN PATIENTS WITH DIABETES MELLITUS TREATED WITH PCI FOR ACUTE CORONARY SYNDROMES IS OBSERVED IN THE SUBGROUP OF PATIENTS WITH IMPAIRED RENAL FUNCTION. RESULTS OF THE ALKK-PCI REGISTRY. J Am Coll Cardiol. 2014;63:A124.

7. Huang Y IDF Diabetes Atlas 8th Edition. (2017).

8. Xueying Qin, PhD; Danyao Jin; Maigeng Zhou, PhD

LiminWang MPH, Pei Gao PhD, Mei Zhang MS, Zhengjing H, Dudan Zhang BS, Qian Deng P, Li Y, Zhenping PhD, Zhao MS; Xueying Qin, PhD; Danyao Jin; Maigeng Zhou, PhD; Xun Tang P, Yonghua Hu MD, LinhongWang P. Prevalence and Ethnic Pattern of Diabetes and Prediabetes in China in 2013. JAMA 317 2515-23 (2017).

9. Zhou M, et al. Prevalence and in - hospital outcomes of diabetes among patients with acute coronary syndrome in China: findings from the Improving Care for Cardiovascular Disease in China Acute Coronary Syndrome Project. Cardiovasc Diabetol 1-14 (2018) doi:10.1186/s12933-018-0793$\mathrm{x}$.

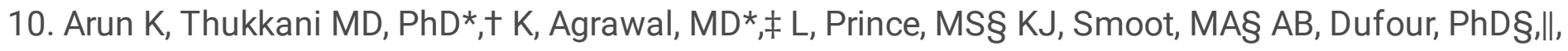
K, Cho MPH, PhD§ DR, Gagnon MD, PhD§, Galina Sokolovskaya, MS§, Samantha Ly, MA*, Sara Temiyasathit, PhD*, DP, Faxon M, Michael Gaziano J, MD, PhD*, $, \S, 9$, and Scott Kinlay, MBBS, P. Long-Term Outcomes in Patients With Diabetes Mellitus Related to Prolonging Clopidogrel More Than 12 Months After Coronary Stenting. J AM Coll Cardiol 66, 1091-1101 (2015).

11. Udell JA, et al. Long-term dual antiplatelet therapy for secondary prevention of cardiovascular events in the subgroup of patients with previous myocardial infarction: a collaborative meta-analysis of randomized trials. Eur Heart J 1-10 (2015) doi:10.1093/eurheartj/ehv443. 
12. Abizaid A, et al. The influence of diabetes mellitus on acute and late clinical outcomes following coronary stent implantation. J Am Coll Cardiol. 1998;32:584-9.

13. Gersh BJ. Incidence, Predictors, and Outcome of Thrombosis After Successful Implantation of DrugEluting Stents. JAMA. 2005;293:260-1.

14. Mauri L, et al. Twelve or 30 months of dual antiplatelet therapy after drug-eluting stents. $\mathrm{N}$ Engl $\mathrm{J}$ Med. 2014;371:2155-66.

15. Wijns W, et al. Endeavour zotarolimus-eluting stent reduces stent thrombosis and improves clinical outcomes compared with cypher sirolimus-eluting stent: 4-year results of the PROTECT randomized trial. Eur Heart J. 2014;35:2812-20.

16. Raymond E, et al. Prasugrel versus Clopidogrel in Patients with Acute Coronary Syndromes. N Engl J Med. 2007;357:2001-15.

17. Huang B, et al. Adverse Cardiovascular Effects of Concomitant Use of Proton Pump Inhibitors and Clopidogrel in Patients with Coronary Artery Disease: A Systematic Review and Meta-Analysis. Arch Med Res. 2012;43:212-24.

18. Bundhun PK, Teeluck AR, Bhurtu A, Huang W. Is the concomitant use of clopidogrel and Proton Pump Inhibitors still associated with increased adverse cardiovascular outcomes following coronary angioplasty ?: a systematic review and meta-analysis of. BMC Cardiovasc Disord 1-11 (2017) doi:10.1186/s12872-016-0453-6.

19. Lettino M. Inhibition of the antithrombotic effects of clopidogrel by proton pump inhibitors: Facts or fancies? Eur J Intern Med. 2010;21:484-9.

20. Harjai KJ, et al. Clinical outcomes in patients with the concomitant use of clopidogrel and proton pump inhibitors after percutaneous coronary intervention: An analysis from the guthrie health offlabel stent (GHOST) investigators. Circ Cardiovasc Interv. 2011;4:162-70.

21. Storey RF, et al. Inhibition of Platelet Aggregation by AZD6140, A Reversible Oral P2Y12 Receptor Antagonist, Compared With Clopidogrel in Patients With Acute Coronary Syndromes. J Am Coll Cardiol. 2007;50:1852-6.

22. Gurbel PA, et al. Randomized double-blind assessment of the ONSET and OFFSET of the antiplatelet effects of ticagrelor versus clopidogrel in patients with stable coronary artery disease: The ONSET/OFFSET study. Circulation. 2009;120:2577-85.

23. Lindholm D, et al. Ticagrelor vs. clopidogrel in patients with non-ST-elevation acute coronary syndrome with or without revascularization: Results from the PLATO trial. Eur Heart J. 2014;35:2083-93.

24. Patti G, di Sciascio G. Meta-analysis: High-dose statin pretreatment prevents periprocedural cardiac events in patients having PCl. Ann Intern Med. 2011;155:20235.

25. Oidor-chan VH, et al. Fenofibrate plus Metformin Produces Cardioprotection in a Type 2 Diabetes and Acute Myocardial Infarction Model. 2016, (2016).

\section{Tables}


Table 1. Demographics of drugs treatment.

\begin{tabular}{|c|c|c|c|c|}
\hline Drug names & $\begin{array}{c}\text { Duration of } \\
\text { drug } \\
\text { treatment }\end{array}$ & $\begin{array}{c}\text { Nubmer of } \\
\text { patients with } \\
\text { clopidogrel<1 year } \\
(\%)\end{array}$ & $\begin{array}{c}\text { Number of } \\
\text { patients with } \\
\text { clopidogrel } 1 \text { year } \\
\text { (\%) }\end{array}$ & $P$ value \\
\hline \multirow{3}{*}{ Metformin } & none & 1089 ( 33.5) & 3032 ( 33.3$)$ & \multirow{3}{*}{0.0346} \\
\hline & $<1$ year & 755 ( 23.2) & 1940 ( 21.3) & \\
\hline & $\geq 1$ year & 1407 ( 43.3) & 4144 ( 45.5$)$ & \\
\hline \multirow{3}{*}{$\begin{array}{l}\alpha \text {-glucosidase } \\
\text { inhibitor }\end{array}$} & none & 791 ( 24.3) & 2126 ( 23.3) & \multirow{3}{*}{0.1094} \\
\hline & < 1year & $723(22.2)$ & 1925 ( 21.1) & \\
\hline & $\geq 1$ year & $1737(53.4)$ & 5065 ( 55.6) & \\
\hline \multirow{3}{*}{$\begin{array}{c}\text { thiazolidinedio } \\
\text { ne (TZD) }\end{array}$} & none & $2878(88.5)$ & $8076(88.6)$ & \multirow{3}{*}{0.3075} \\
\hline & $<1$ year & $227(7.0)$ & $679(7.4)$ & \\
\hline & $\geq 1$ year & $146(4.5)$ & $361(4.0)$ & \\
\hline \multirow{3}{*}{ Sulfonylureas } & none & $1873(57.6)$ & $5252(57.6)$ & \multirow{3}{*}{0.4824} \\
\hline & $<1$ year & 559 ( 17.2$)$ & 1496 ( 16.4) & \\
\hline & $\geq 1$ year & 819 ( 25.2) & $2368(26.0)$ & \\
\hline \multirow{3}{*}{ Glinides } & none & $2776(85.4)$ & 7759 ( 85.1) & \multirow{3}{*}{0.8629} \\
\hline & $<1$ year & $265(8.2)$ & $743(8.2)$ & \\
\hline & $\geq 1$ year & $210(6.5)$ & $614(6.7)$ & \\
\hline \multirow{3}{*}{$\begin{array}{l}\text { DPP-4 } \\
\text { inhibitor }\end{array}$} & none & 3056 ( 94.0) & 8589 ( 94.2) & \multirow{3}{*}{0.3037} \\
\hline & $<1$ year & $178(5.5)$ & $497(5.5)$ & \\
\hline & $\geq 1$ year & $17(0.5)$ & $30(0.3)$ & \\
\hline \multirow{3}{*}{ insulin } & none & $1835(56.4)$ & $5193(57.0)$ & \multirow{3}{*}{0.5542} \\
\hline & $<1$ year & $351(10.8)$ & $923(10.1)$ & \\
\hline & $\geq 1$ year & 1065 ( 32.8) & 3000 ( 32.9$)$ & \\
\hline
\end{tabular}




\begin{tabular}{|c|c|c|c|c|}
\hline Drug names & $\begin{array}{l}\text { Duration of } \\
\text { drug } \\
\text { treatment }\end{array}$ & $\begin{array}{c}\text { Nubmer of } \\
\text { patients with } \\
\text { clopidogrel<1 year } \\
(\%)\end{array}$ & $\begin{array}{c}\text { Number of } \\
\text { patients with } \\
\text { clopidogrel } \geq 1 \text { year } \\
\text { (\%) }\end{array}$ & $P$ value \\
\hline \multirow{3}{*}{ ticagrelor } & none & $3122(96.0)$ & 9029 ( 99.0) & \multirow{3}{*}{$<0.0001$} \\
\hline & $<1$ year & $114(3.5)$ & $85(0.9)$ & \\
\hline & $\geq 1$ year & $15(0.5)$ & $2(0.1)$ & \\
\hline \multirow{3}{*}{ ARB/ACEI } & none & 499 ( 15.3) & $1463(16.0)$ & \multirow{3}{*}{0.0077} \\
\hline & $<1$ year & 690 ( 21.2) & 1706 ( 18.7) & \\
\hline & $\geq 1$ year & $2062(63.4)$ & $5947(65.2)$ & \\
\hline \multirow{3}{*}{$\mathrm{CCB}$} & none & $922(28.4)$ & $2461(27.0)$ & \multirow{3}{*}{0.0011} \\
\hline & $<1$ year & 757 ( 23.3) & 1915 ( 21.0) & \\
\hline & $\geq 1$ year & $1572(48.4)$ & $4740(52.0)$ & \\
\hline \multirow{3}{*}{$\begin{array}{l}\beta \text { receptor } \\
\text { blocker }\end{array}$} & none & $317(9.8)$ & $883(9.7)$ & \multirow{3}{*}{$<0.0001$} \\
\hline & $<1$ year & $566(17.4)$ & 1190 ( 13.1) & \\
\hline & $\geq 1$ year & $2368(72.8)$ & 7043 ( 77.3) & \\
\hline \multirow{3}{*}{ diuretic } & none & $1802(55.4)$ & $5110(56.1)$ & \multirow{3}{*}{0.6018} \\
\hline & $<1$ year & $827(25.4)$ & 2238 ( 24.6$)$ & \\
\hline & $\geq 1$ year & $622(19.1)$ & $1768(19.4)$ & \\
\hline \multirow{3}{*}{ statin } & none & $11(0.3)$ & $29(0.3)$ & \multirow{3}{*}{$<0.0001$} \\
\hline & $<1$ year & $202(6.2)$ & $249(2.7)$ & \\
\hline & $\geq 1$ year & 3038 ( 93.4) & 8838 ( 97.0) & \\
\hline \multirow{3}{*}{ nitrate } & none & 377 ( 11.6) & $808(8.9)$ & \multirow{3}{*}{$<0.0001$} \\
\hline & $<1$ year & $1248(38.4)$ & 2841 ( 31.2$)$ & \\
\hline & $\geq 1$ year & $1626(50.0)$ & $5467(60.0)$ & \\
\hline \multirow{3}{*}{ PPI } & none & 1288 ( 39.6) & $3700(40.6)$ & \multirow{3}{*}{0.0597} \\
\hline & $<1$ year & 1427 ( 43.9) & 3797 ( 41.7$)$ & \\
\hline & $\geq 1$ year & $536(16.5)$ & 1619 ( 17.8$)$ & \\
\hline
\end{tabular}

\section{Figures}




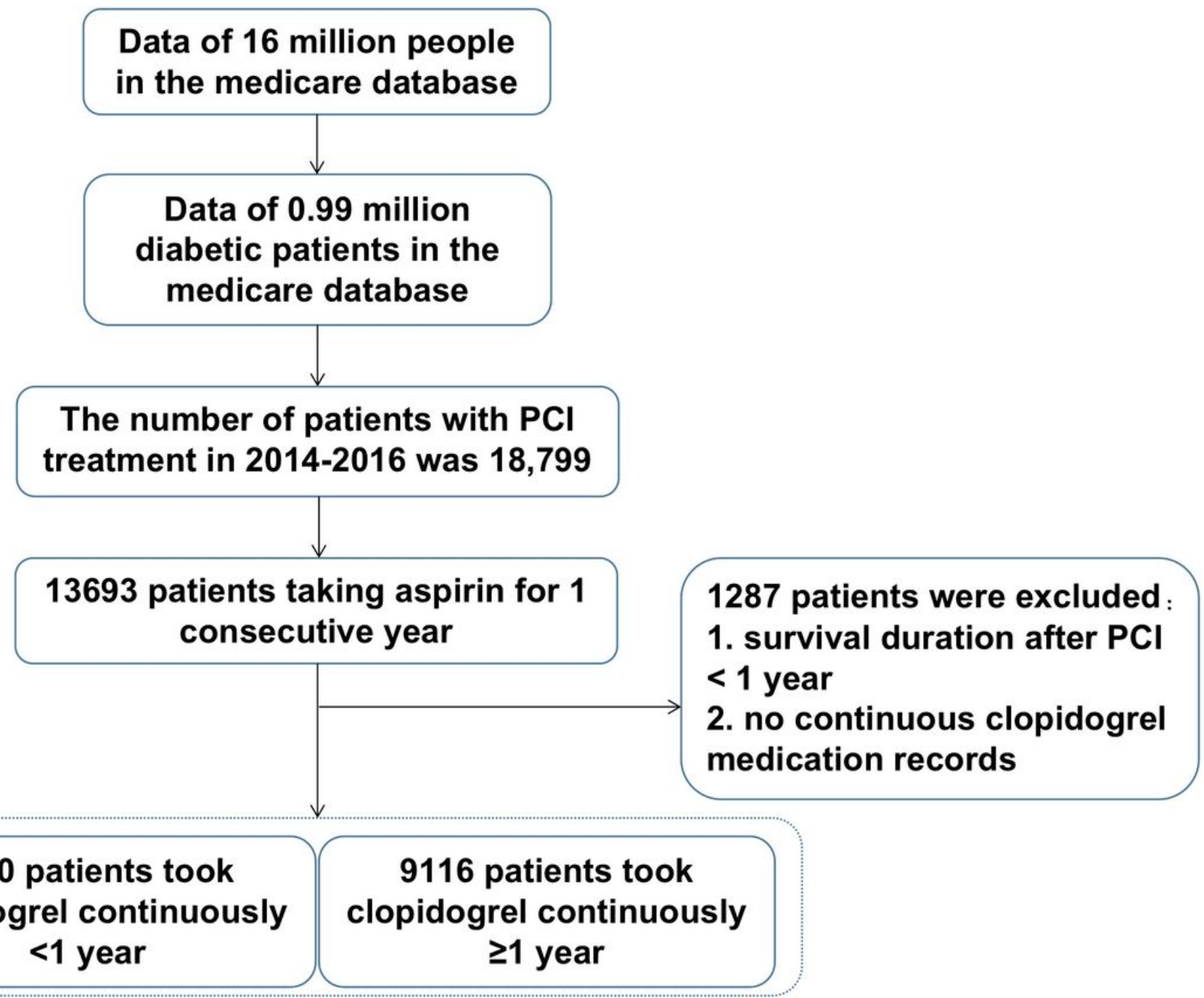

Figure 1

Selection process of included patients. 


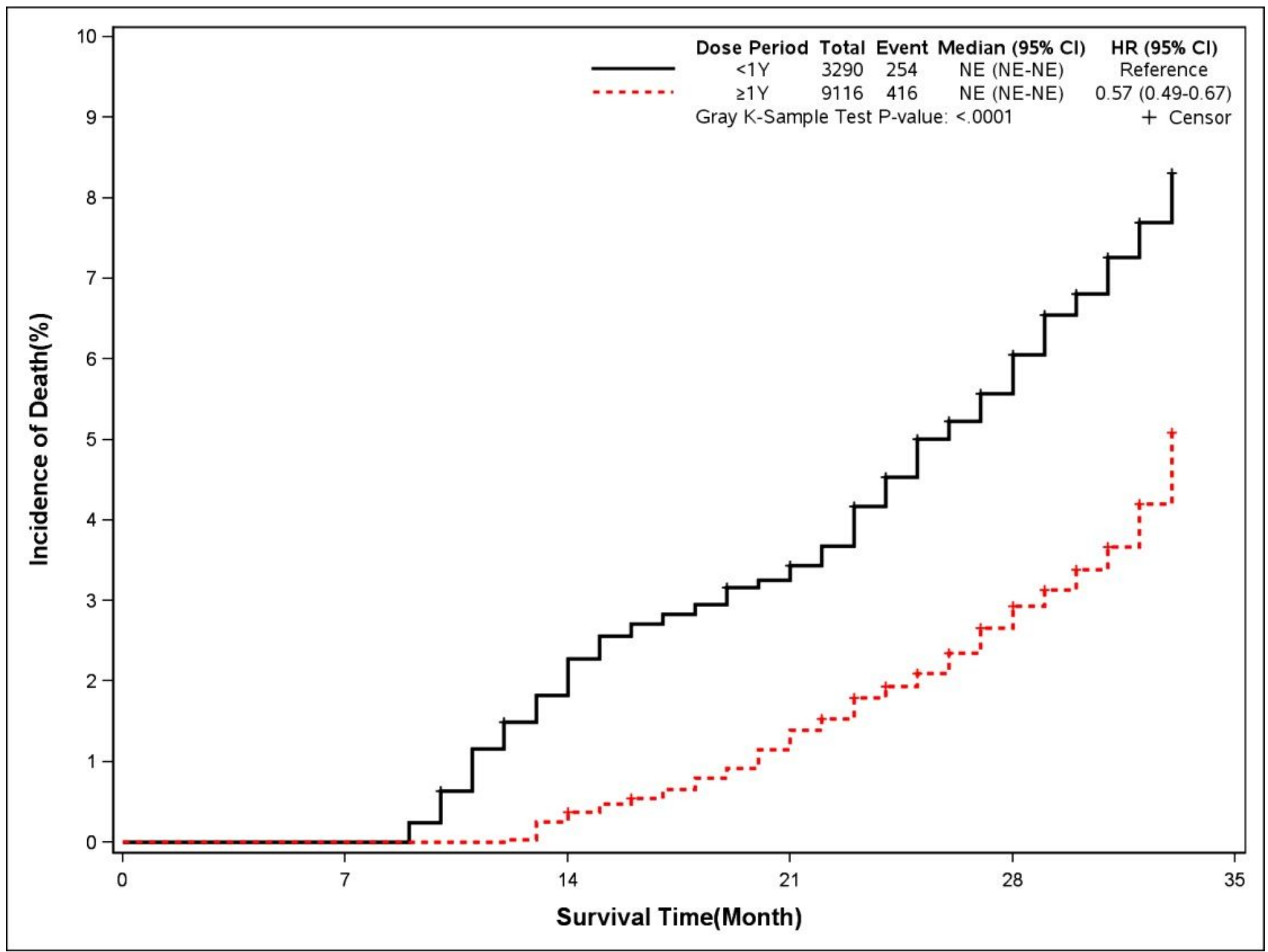

Figure 2

Incidence of all-cause death in two groups. Black line: patients took clopidogrel continuously < 1 year; Red line: patients took clopidogrel continuously $\geq 1$ year. 


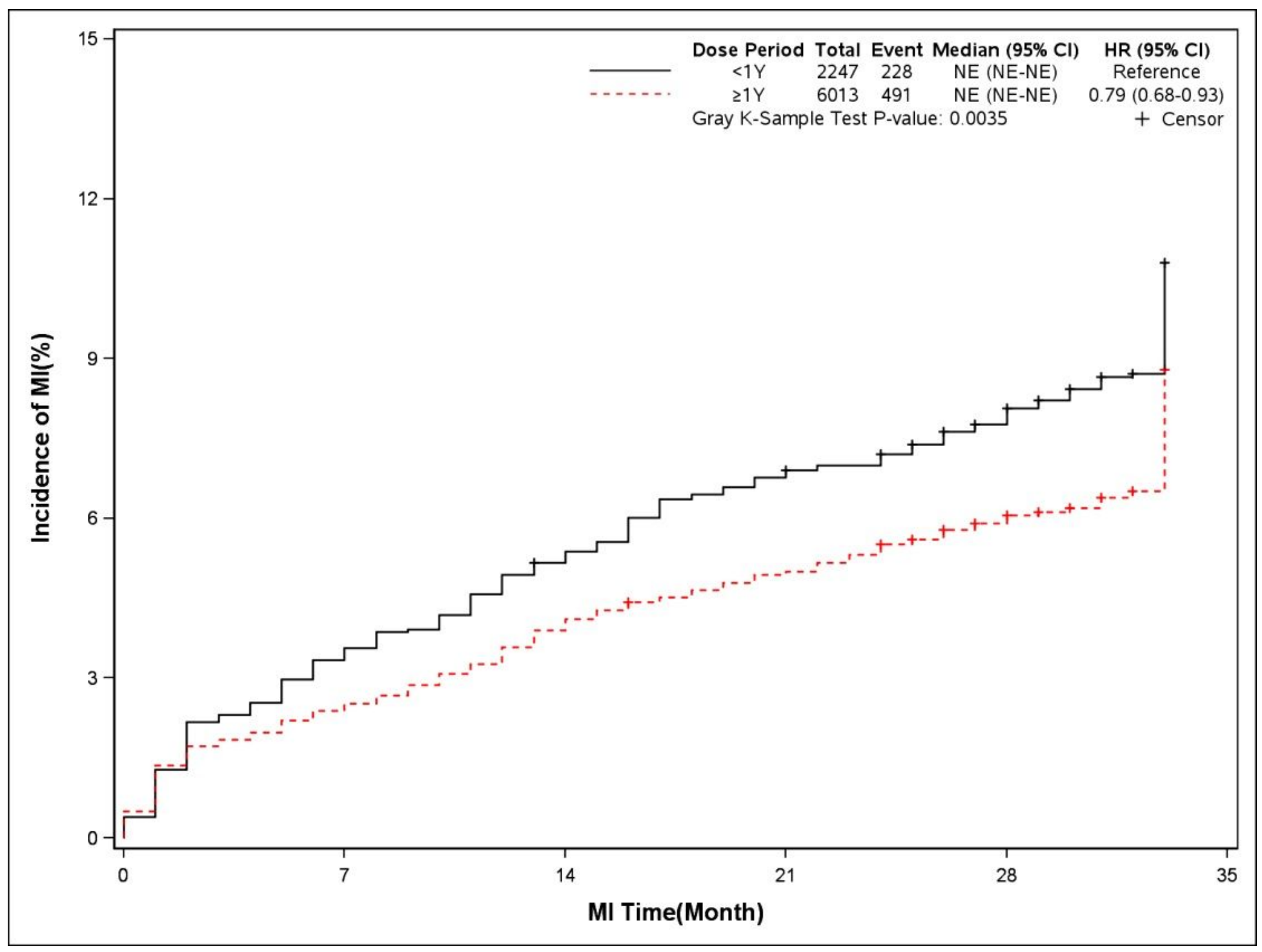

Figure 3

Incidence of recurrent myocardial infarction in two groups. Black line: patients took clopidogrel continuously $<1$ year; Red line: patients took clopidogrel continuously $\geq 1$ year. 


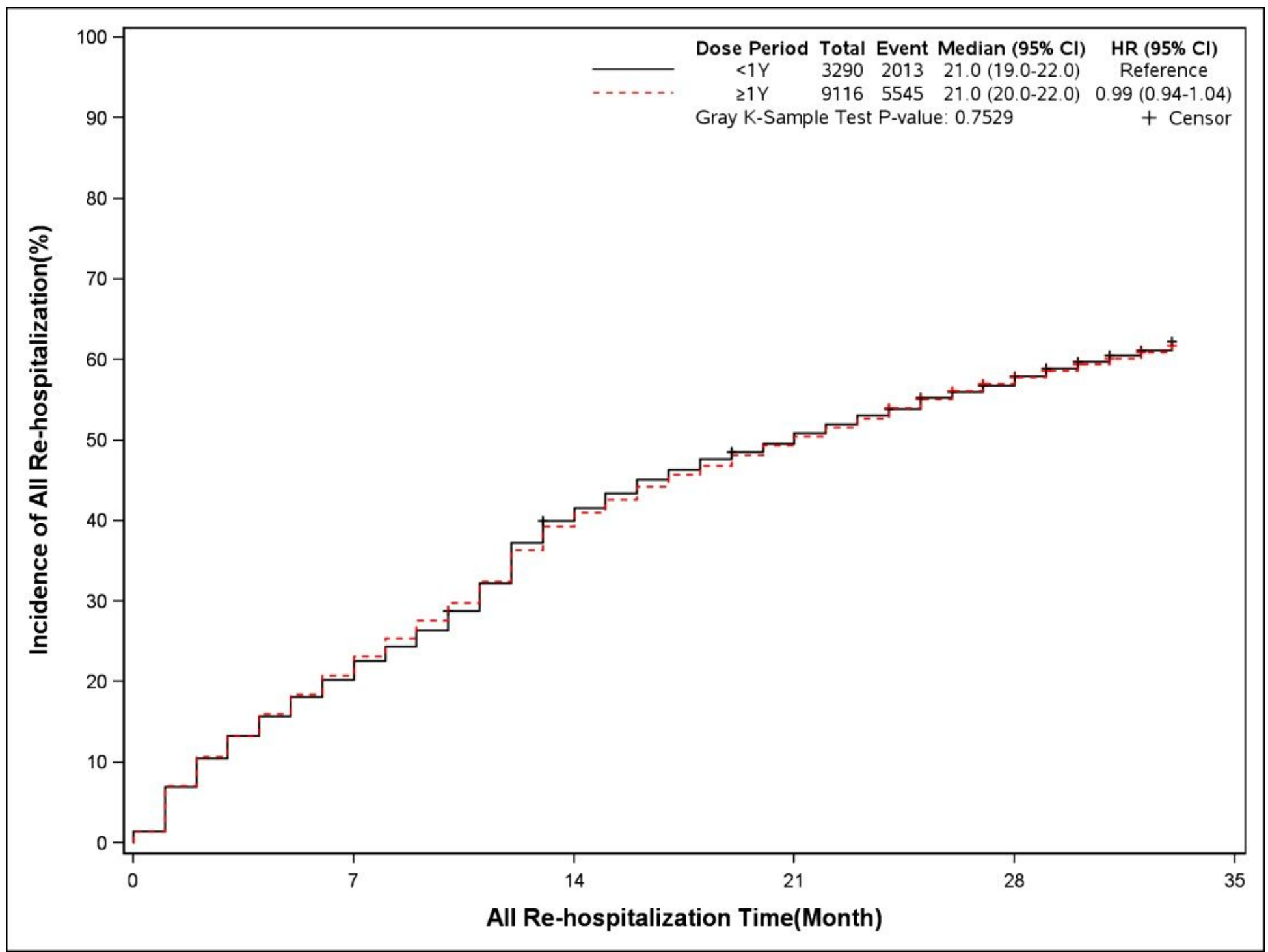

Figure 4

Incidence of all-cause rehospitalization in two groups. Black line: patients took clopidogrel continuously < 1 year; Red line: patients took clopidogrel continuously $\geq 1$ year. 


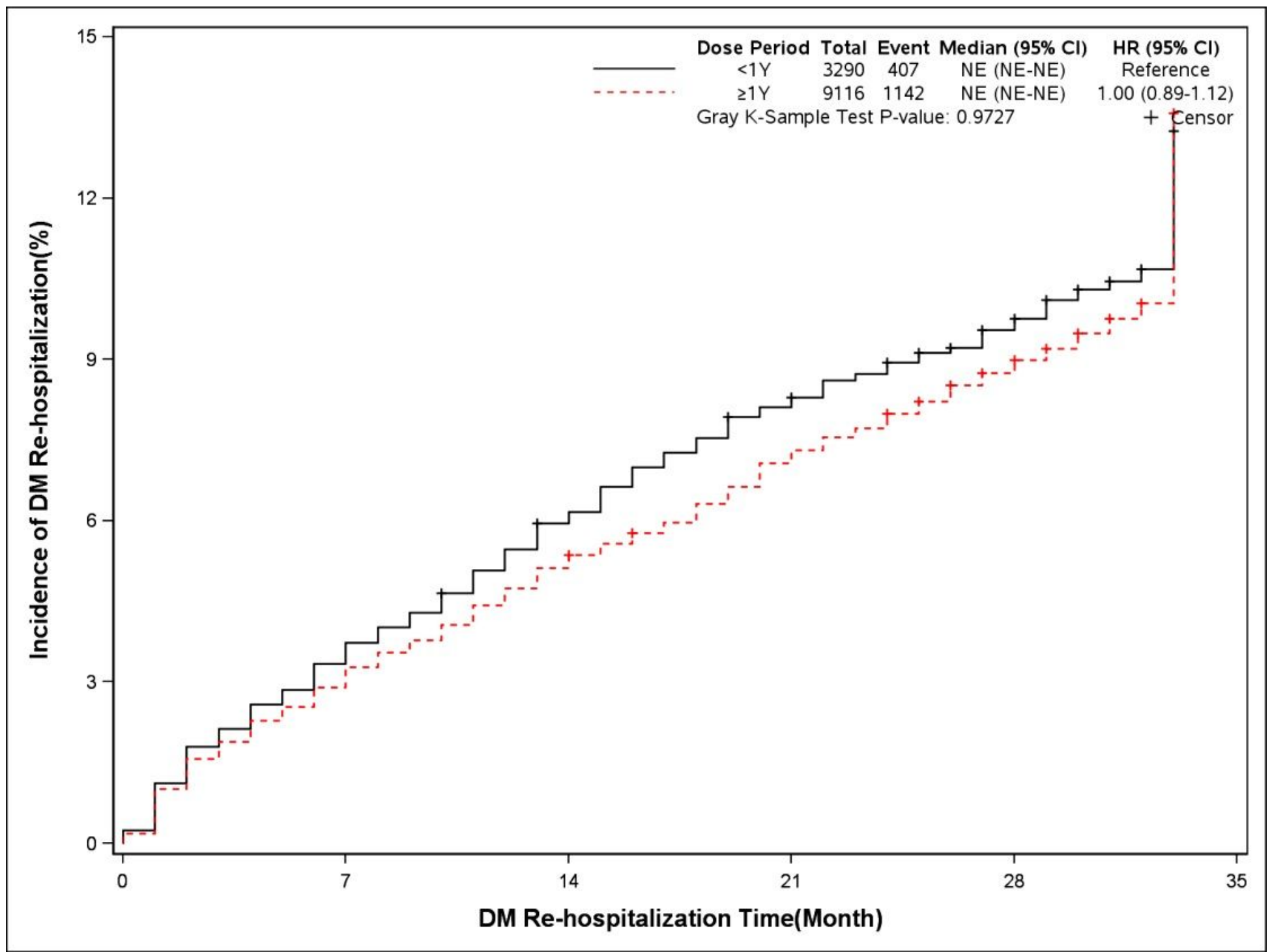

Figure 5

Incidence of diabetes-related rehospitalization in two groups. Black line: patients took clopidogrel continuously < 1 year; Red line: patients took clopidogrel continuously $\geq 1$ year. 


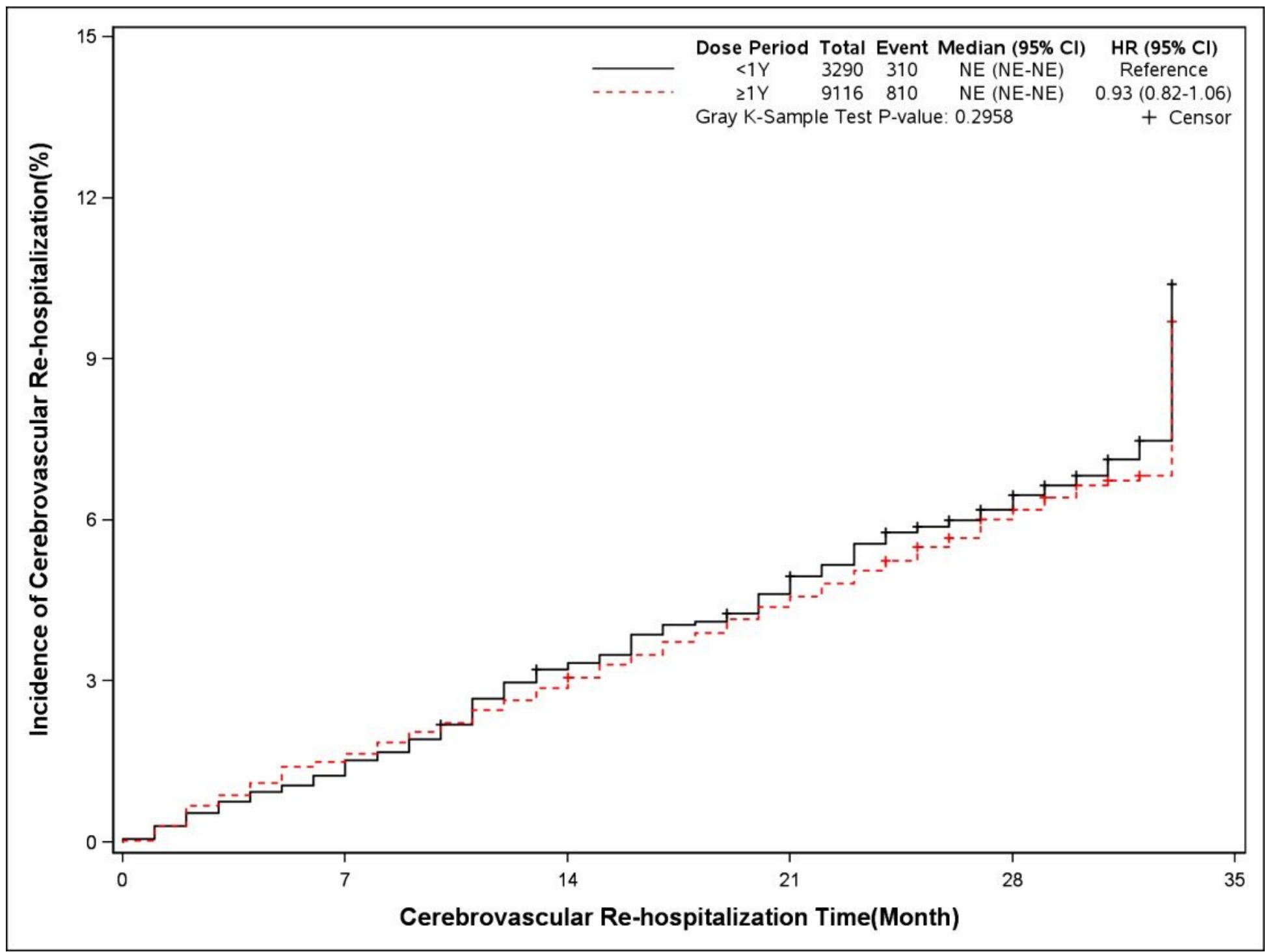

Figure 6

Incidence of cerebrovascular rehospitalization in two groups. Black line: patients took clopidogrel continuously < 1 year; Red line: patients took clopidogrel continuously $\geq 1$ year. 


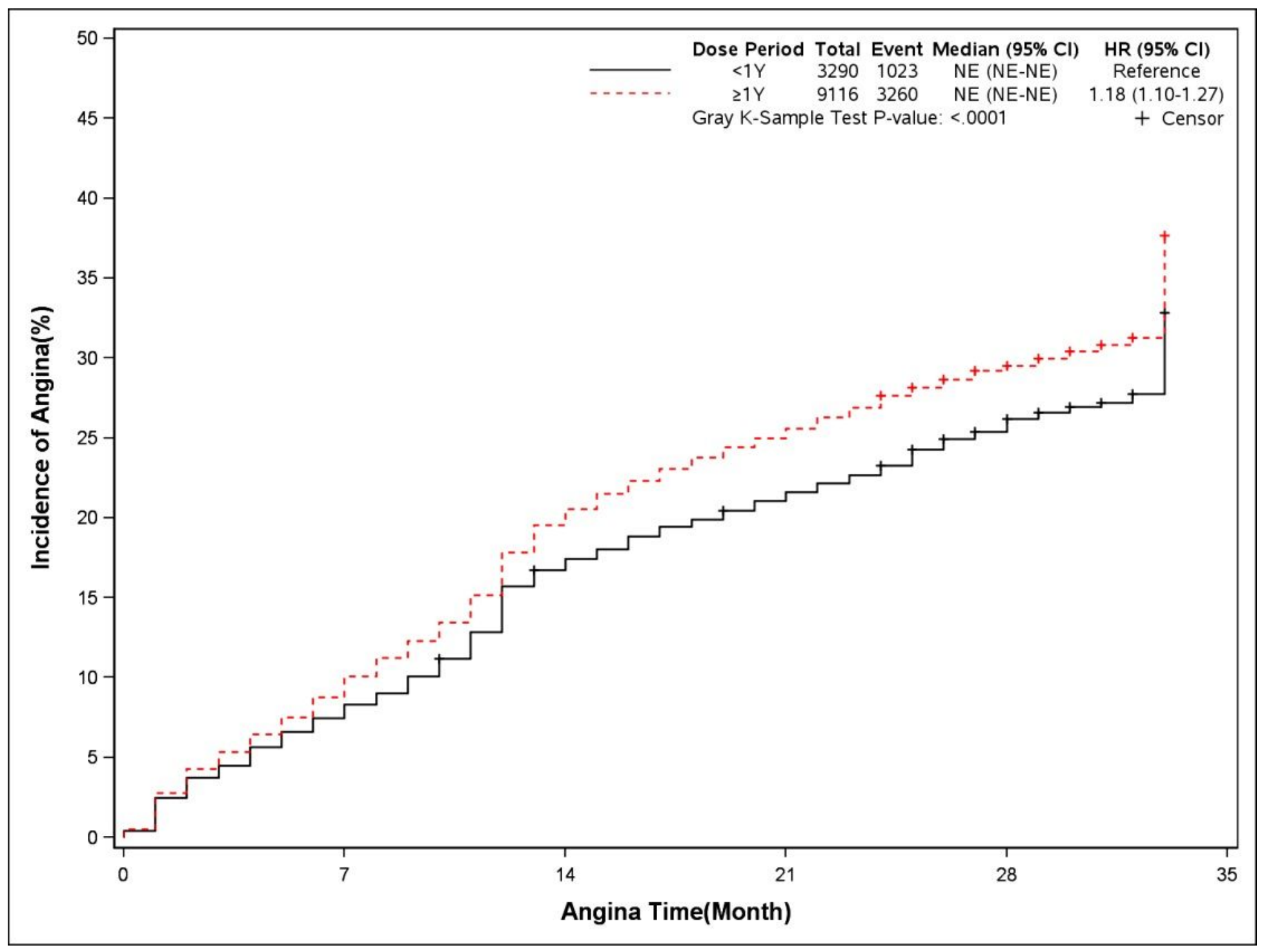

Figure 7

Incidence of angina in two groups. Black line: patients took clopidogrel continuously < 1 year; Red line: patients took clopidogrel continuously $\geq 1$ year. 


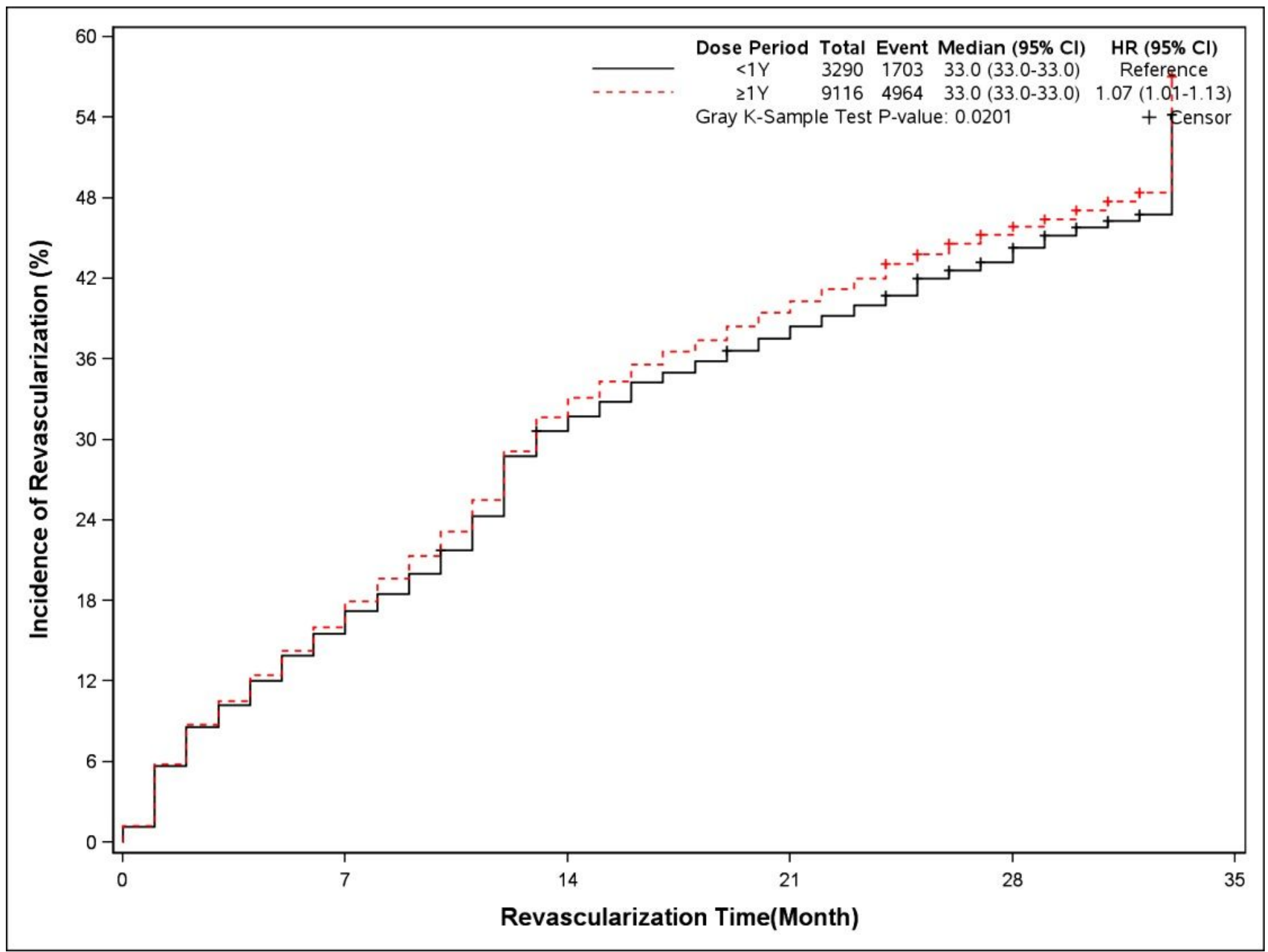

Figure 8

Incidence of revascularization in two groups. Black line: patients took clopidogrel continuously < 1 year; Red line: patients took clopidogrel continuously $\geq 1$ year. 